\title{
How should doctors approach patients? A Confucian reflection on personhood
}

Daniel Fu-Chang Tsai National Taiwan University Hospital, Taipei, Taiwan, Republic of China

\begin{abstract}
The modern doctor-patient relationship displays a patient-centred, mutual-participation characteristic rather than the former active-passive or guidance-cooperation models in terms of medical decision making. Respecting the wishes of patients, amounting to more than mere concern for their welfare, has become the feature central to certain modern bioethics theories. A group of ethical principles such as respect for autonomy, beneficence, non-maleficence, and justice has been proposed by bioethicists and widely adopted by many medical societies as an ethical guide to how doctors, in their daily practice, should treat their patients. However, seeing patients as persons who are rational, self-conscious beings capable of valuing their own lives, and who are consequently entitled to the liberty and rights to choose for themselves, is in general the backbone of Western bioethical principles. Since Confucian philosophy has long been a representative of the East-Asia cultural tradition and Confucian bioethics has recently been developed as a theory of applied ethics, examining Confucius's idea of "persons" may shed some light on the current bioethical debates. Confucius's concept of persons, which is best interpreted via his theories of

"chun-tze", (the morally ideal person) encapsulating a two-dimensional approach, (the "autonomous person" and the "relational person"), provides a more comprehensive model regarding what a person is and how he/she should be treated. This two-dimensional approach sees a person not only as a rational, autonomous agent but also as a relational, altruistic identity whose self actualisation involves incessant participating in and promoting of the welfare of his fellow persons. Hence this may balance the current bioethical trend whereby "respect for autonomy" often triumphs.
\end{abstract}

(Fournal of Medical Ethics 2001;27:44-50)

Keywords: Personhood; autonomy; Confucian ethics; physician-patient relationship; principle-oriented bioethics

Bioethical problems arise within any society whether it be biotechnologically advanced or not. However, the more a society becomes biotechnologically advanced, the more the number of bioethical issues and their importance tend to increase. The attention-grabbing bioethical issues such as "animal or human cloning", "artificial reproduction", "designer children", "surrogate motherhood", "xenotransplantation", and "geneti- cally modified food" may have great impact on the future of human society, and have therefore attracted the spotlight on the stage of bioethicsthey interest both the academics and the general public. Yet the majority of bioethical problems occur in day-to-day medical decision making and remain within the boundaries of the relationships between health care professionals, patients and their families.

\section{The physician-patient relationship and the principles of medical ethics}

In 1955, Szasz and Hollender proposed three models of the doctor-patient relationship, namely the "activity-passivity model", the "guidancecooperation model", and the "mutual participation model", which simulate respectively the prototype of parent-infant, parent-child (adolescent) and adult-adult models of communication. ${ }^{1}$ However, the consumer movement of the $60 \mathrm{~s}$ and $70 \mathrm{~s}$ promoted the "mutual participation relationship" between doctors and patients, and the traditional paternalistic models were in general refuted by modern bioethics. Respecting the wishes of patients more than merely promoting their welfare has increasingly become central to certain Western bioethics theories.

On the other hand, one may consider the question "how should doctors approach their patients" now being answered by a principlesoriented bioethics. In other words, moral principles are used as the ethical guidelines for medical practice and research, which concomitantly defines how doctors should treat their patients. Different authors have proposed different moral principles. For example, Beauchamp and Childress put forward the principle of "respect for autonomy, beneficence, non-maleficence, and justice" as the principles of biomedical ethics. ${ }^{2}$ Downie and Calman indicated the principles of "utility, justice, non-maleficence, compassion (benevolence), and self-development", governed by the principle of "respect for the autonomous individual" as the consensus principles. ${ }^{3}$ Engelhardt suggested the principles of "permission" and "beneficence" as the principles of bioethics. ${ }^{4}$ Veatch identified a set of moral principles which included "utility, veracity, fidelity to promises, avoid killing, justice, and autonomy" as principles of right actions..$^{5}$ Macer has argued that love should be the foundation of bioethics, and presented his bioethical principles in various forms of love, namely "self-love (au- 
tonomy), love of others (justice), loving life (do no harm), and loving good (beneficence)" ${ }^{6}$ Although different authors have proposed different sets of bioethical principles, these sets of principles are actually very similar.

If one concentrates on Beauchamp and Childress's four-principles approach to bioethics, which literally can be regarded as the origin of the principles-oriented bioethics method, one can have a fair idea of "how doctors should approach their patients" as prescribed by modern Western bioethics. First, is respect for autonomy: patients who are competent to make decisions should have a right to, and physicians should have the concomitant duty to respect their preferences regarding their own health care. Second, is non-maleficence: not causing harm, balancing benefit over harm to produce the maximal good for the patients. Third, is beneficence: to be concerned with and promote the welfare of patients. Fourth, is justice: fair, equitable and appropriate treatment in the light of what is due or owed to patients.

These four principles have played a large role in modern Western bioethics and have been adapted by many medical societies in North America as their professional code of practice (regardless of the fact that "principlism" has been criticised by many moral philosophy theorists). For example, the American Counselling Association gave "autonomy, non-maleficence, beneficence, justice and fidelity" as their "moral principles for the practitioner's guide to ethical decision making" in 1996. The American Dental Association indicated that "patient autonomy, non-maleficence, beneficence, justice, and veracity" were their "principles of ethics and code of professional conduct" in 1998. Many other societies, such as the American Academy of Family Physicians, ${ }^{10}$ the American College of Emergency Physicians, ${ }^{11}$ and the TriCouncil Working Group of Canada, ${ }^{12}$ all established their "professional codes of ethics" with reference to the "four principles" with more or less modification. These can be seen as representing the Western bioethics approach to "how doctors should approach their patients". However, if one investigates the metaphysical foundation of the four principles, one can see that regarding "persons" as moral agents bearing the capacity of self consciousness, rationality and the ability to value their own lives, constitutes the moral justification for respecting a person's wishes and promoting his welfare Furthermore, since persons are generally born with such moral capacities and are thus similar to each other, they deserve to be considered as equals and to be treated with fairness.

\section{Why Confucius's ethics?}

Confucius is one of the most influential thinkers of Eastern philosophy and a representative of Eastern culture. Among the world's great philosophers, Confucius, together with Socrates, Gautama Buddha, and Jesus Christ were regarded as the four paradigmatic individuals by Jaspers, because of their extended influence through two millennia and their extraordinary importance for all philosophy. ${ }^{13}$ A brief comparison with Socrates may give us a prima facie idea of Confucius since Socrates is generally called "the Western Confucius" and Confucius, "the Eastern Socrates". They were both earnest and devoted teachers, and interested in the problems of man; they both established ethical theories which were not based on religion; they both advocated the necessity for rulers of competence and virtue; they both demonstrated sensibility and the common touch, and they were both already famous before their death. They were different in the following aspects: Confucius took the position of preserving and embellishing traditional cultures, yet Socrates was sceptical and critical of them; Confucius was of the style that strove to save the country and people, whereas Socrates deeply revered the love of wisdom; Confucius emphasised personal reflection in the pursuit of a reasonable social life, while Socrates emphasised the importance of "definition" and sought accuracy of knowledge and thought. ${ }^{14}$

Confucianism has been the dominant ideology in Chinese philosophy since the Han Dynasty (206BC 220AD) and has directed social, political, educational, and moral thoughts in Chinese society. ${ }^{15}$ The author has argued that ancient Chinese medical ethics was also established on the foundation of Confucian ethics. ${ }^{16}$ Under the influence of certain Confucian ideology, Chinese physicians were respected as highly as the Confucian politicians who were able to accomplish their aspiration to bring peace and prosperity to people. Therefore, they were expected to be virtuous to the point of achieving the moral standard of an ideal Confucian person, "chun-tzu" (the superior man). Since the concept of persons plays such a fundamental role in modern Western bioethics, examining Confucius's idea of persons may shed some light on current bioethical debates.

\section{Persons in modern Western bioethics}

The complex and diverse conceptions of "personhood" have led to deep controversies in Western philosophy in general and bioethics in particular. Traditional thinking presupposes all human beings - the species homo sapiens - are persons and that this is an indisputable, self-evident truth. Devine described this as the "species principle": human organisms, no matter their degree of maturity or decay, are persons, whereas non-human animals, robots, or extraterrestrial life cannot be persons. ${ }^{17}$ Since the Judaeo-Christian tradition sees human beings as having been created in the image of God, and human dignity and rights flowing from God's creation, they also assert that all human beings are persons. However, these traditionalist conceptions of personhood are challenged by bioethical dilemmas. Should an embryo or fetus, without any likeness to human beings, share the same dignity and rights as persons? Can someone who is in a permanent vegetative state, having lost his or her consciousness and rationality forever, still be treated as a person? 
Philosophers and bioethicists who took a liberal point of view argued against the traditional position and separated "persons" from "human beings". That is to say that if a "human being" were not at the same time a "person", he would have no human rights. As Engelhardt suggests: "Persons, not humans, are special". ${ }^{18}$ Nevertheless, how is "person" defined? In modern Western philosophy, Descartes defined a "person" as a "thinking thing". John Locke identified a person as "a thinking intelligent being that has reason and reflection and can consider itself, the same thinking thing, in different times and places", whereas "human being" only means a corporeal existence. ${ }^{19}$ Most importantly, according to Kant, a person is a rational agent capable of acting freely and autonomously.

In modern bioethics, Singer distinguished two meanings of human beings - one, a member of the species homo sapiens, two, a being who possesses certain qualities such as "self-awareness, selfcontrol, a sense of the future, a sense of the past, the capacity to relate to others, concern for others, communication and curiosity" which was a list proposed by Fletcher as constituting the "indicators of humanhood". ${ }^{20}$ As Singer defined it, only human beings in the second sense are "persons", and thus deserving of rights and respect. He then suggested that "rationality" and "selfconsciousness" are the crucial characteristics of persons.

Warren also distinguished a "genetic sense" and a "moral sense" of being human and pointed out that the feature of "consciousness and the capacity to feel pain" could constitute personhood. ${ }^{21}$ Tooley indicated that a person must have the "awareness of self as a continuing entity" and be "capable of having an interest in his own continued existence". ${ }^{22}$ Harris argued that a person is "any being capable of valuing its own existence". ${ }^{23}$ Engelhardt proposed that those who have the four characteristics: self consciousness, rationality, freedom to choose, and being in possession of a sense of moral concern, are "persons in the strict sense". While human beings such as infants, the profoundly mentally retarded, the permanently comatose, and individuals with advanced Alzheimer's disease, who lack those characteristics, are merely persons in a social sense. ${ }^{24}$

Although these conceptions placed different emphasis on what should be counted as the standards of personhood, they all stress that "rationality, self-consciousness, and autonomous moral agency" are the key features of persons. In other words, modern bioethics principles are established on the foundation that persons are rational, self-conscious, autonomous moral agents who have liberty and the right to choose for themselves, and should therefore be treated equally and with the utmost respect.

\section{Confucius's concept of persons}

Confucius's concept of persons is expressed in his moral ideal of a chun-tze. Chun-tze in Confucius's ethics is the man of high moral achievement who constantly tries to improve and cultivate himself to attain various stages of perfection. $\mathrm{He}$ is the embodiment of Confucius's moral ideal of man. Many characteristics of a chun-tze reflect thoroughly the distinctive features of an autonomous person.

\section{CHUN-TZE AS AN AUtONOMOUS PERSON: THE} VERTICAL DIMENSION OF PERSONS

The concept of chun-tze comprises various meanings that are commensurate with the idea of autonomous persons. Firstly, self activation: in the Book of Change it is said: "Heaven, in its motion, gives the idea of strength. Chun-tze, in accordance with this, nerves himself to ceaseless activity". ${ }^{25}$ In order to undergo this unceasing self renewal by imitating the constant running of the celestial planets, chun-tze has to be a man of self activation and perseverance.

Secondly, self cultivation: Confucius said: "When substance exceeds refinement, one becomes rude. When refinement exceeds substance, one becomes urbane. It is only when one's substance and refinement are properly blended that one becomes a superior man" ${ }^{26}$ This indicates that a superior man needs to cultivate himself and find a balance between "unadorned human nature" and "moral and social cultivation".

Thirdly, self reflection: Mencius said: "If a man love others, and no responsive attachment is shown to him, let him turn inwards and examine his own humaneness (jen). If he is trying to rule others, and his government is unsuccessful, let him turn inwards and examine his wisdom. If he treats others politely (ii), and they do not return his politeness, let him turn inwards and examine his own feeling of respect. When we do not, by what we do, realise what we desire, we must turn inwards, examine ourselves in every point." 27

Fourthly, self reliance: the superior man seeks in himself, not in others ${ }^{28}$; he worries only about his own inability, not about others' failure to understand him. ${ }^{29}$ Neither would he blame Heaven or others for his own failure, ${ }^{30}$ nor does he rely on others for his success; he is a man of self reliance. Mencius described chun-tze as the man "whose heart cannot be dissipated by the power of wealth and honours, who cannot be influenced by poverty or humble stations, who cannot be subdued by force and might". ${ }^{31}$ This capacity to withstand the trials of both adversity and prosperity, to resist the controlling forces of temptation, coercion and manipulation, reveals that the person is possessed of the qualities of self reliance, self determination, and a strong moral will.

Fifthly, moral authenticity: Confucius emphasised that the moral characters of a chun-tze must be authentic, not merely a conformity to the social norm. He said: "He who puts on an appearance of stern firmness, while inwardly he is weak, is like one of the small mean men; yea, is he not like the thief who breaks through, or climbs over a wall"? "Your good, careful [hypocritical] people of the village (hsiang yuan) are the thieves of virtue." 33 "A man with clever words and an ingratiating appearance is seldom a man of humaneness." 34 "A man who is 
strong, resolute, simple, and slow to speak is near to humaneness." ${ }^{35}$ Confucius hated hypocrites and reprehended those who spoke eloquently and behaved ingratiatingly towards the public yet lacked the genuine concern of humaneness and moral authenticity inside; he called them the "thieves of virtue".

In summary, the superior man sees himself as the master of his own life and attributes all responsibilities to himself and not to someone else. He is a self starter and self legislator, and refuses to be controlled or coerced by others. The goal of Confucius's moral philosophy and moral education in reality is to create an autonomous person who is selfactivated, self-determined, self-reliant, and is constantly improving himself via moral self cultivation.

Apart from being an autonomous person, chun-tze has another prominent feature as emphasised in Confucius's ethics, that is, the relational perspectives.

2. CHUN-TZE AS A RELATIONAL PERSON: THE HORIZONTAL DIMENSION OF PERSONS

The central theme of Confucius's ethics, "humaneness (jen)", which in the Chinese character means two persons and is pronounced in the same way as the Chinese word "human", reflects the idea of relational personhood because the Chinese conception of man is based on "the individual's transactions with his fellow human beings". ${ }^{36}$ The Chinese word "lun-li" (ethic), which implies the "reason or logic" (li) of "human relationship" (lun), is not quite the same as "dao-der" (morality) which, verbatim, indicates "the way" (dao) of virtue (der), whereas in English "morality" and "ethics" have quite similar meanings and are usually interchangeable. "Ethics" in Chinese simply directs one towards the ideal interpersonal relationship, as the author defines it-the "horizontal dimension" of being a person. In contrast, both the modern bioethical conceptions of personhood which focus on self consciousness, rationality and the autonomous moral agent, and the Judaeo-Christian tradition, which see persons as a creation in God's image that reflects God's glory, primarily refer to the "vertical dimension" of being a person. This is an interesting contrast. ${ }^{37}$

According to Fingarette's understanding of persons in the Confucian sense, "man is not an ultimately autonomous being who has an inner and decisive power, intrinsic to him, a power to select among real alternatives and thereby to shape a life for himself. Instead he is born as 'raw material' who must be civilized by education and thus become a truly human being." ${ }^{.38}$ Liang made clear that "... in Chinese thinking, individuals are never recognised as separate entities; they are always regarded as part of a network, each with a specific role in relation to others" ${ }^{39}$ He proposed that the traditional Chinese is neither individual-based nor society-based, but relational-based. ${ }^{40} \mathrm{Tu}$ also pointed out that "self" in the classical Confucian sense is both "a centre of relationships" and "a dynamic process of spiritual development" ": whereas "one becomes fully human through continuous interaction with other human beings and one's dignity as a person depends as much on communal participation as on one's own sense of self-respect". ${ }^{2}$

In other words, a Confucian person is socially situated, defined, and shaped in a relational context where he must achieve humaneness (jen) through interaction with other particular individuals. ${ }^{43}$ Put differently, "the self develops its contours, unfolds its characteristics, takes shape, becomes actual and individuated through engaging and interacting in a network of relations with others ... Selfindividuation is possible only through a process of engagement with others within the context of one's social roles and relationships". ${ }^{44}$ This concept echoes the original Latin term of person, (persona) meaning a theatrical mask worn by an actor in classical drama. By putting on masks the actors signified that they were acting a role, hence person came to mean one who plays a role in life. ${ }^{4}$

In contrast, the classical liberal tradition emphasises that persons are autonomous, rational, and self-conscious individuals who are "making context-free choices in a conceptual vacuum" ${ }^{\prime 46}$ and capable of identifying and pursuing their own good. Being conceived as sovereign agents of choices, persons hence deserve equal concern and respecttheir rights and privacy are inviolable; even a collective goal and the collective good are not sufficient reasons to compromise them. In other words, it is a person's separateness, individuality, and distinctiveness rather than his relatedness, mutuality, and communion with others that are valued. To sum up this general contrast between Chinese and the West, using Hansen's description: "Western theorists have understood the world as made up of particulars. Chinese metaphysical theory analyses objects as parts carved out of a large, more basic whole". ${ }^{47}$

\section{SELFHOOD}

Apart from stressing the relatedness rather than separateness of personhood, two more points concerning Confucian selfhood should be briefly mentioned here. Firstly, the boundaries between self and others in Chinese philosophy are not always clear: Dao, in Chinese philosophy, signifies the supreme metaphysical force that exists everywhere in everything and dominates the exercise and functioning of all things in the universe. Humankind, being bred and activated by this power, inherits the infinite potential of dao. In other words, dao is embodied in a person's selfhood as well as existent in every other being. For this reason, the boundaries between the creator and the created, the cosmos and the individual, the "selfness" and "otherness" are not always clear. As Elvin said: "Perhaps this absence of alienation from the world gave the self in China slightly less sharply defined margins than it had in the West. For the Chinese, this life was neither a vale of tears, nor a testing-ground, but a home" ${ }^{48}$ The self, as the centre of relations, is not merely "a privatised self, the small self and a self that is a closed system". Instead, it can be and should be broadened to become a public-spirited, 
great self and a self that is an open system, ${ }^{49}$ and deepen in self transformation through genuine communication with others. Family, community, country and the world, from the Confucian point of view, are spheres of selfhood where one engages in promoting them and transforming oneself.

Secondly, the Confucian self searches in unity with dao: dao also symbolises the universal mora order and the ideal status of moral achievement for man to define, pursue and accomplish. Metaphysically, man realises his true self, the "true manhood" when he lives in unity and harmony with dao. Put differently, the universal moral order is a purpose that invites and demands the participation of man; man is likewise inspired by the dao in his ceaseless pursuit and transformation to be in unity with dao. Therefore, the self in Confucius's ethics is not alienated from the universe, and nor is the universe lifeless and soulless but, instead, lively and purposive. The true self, in its sincere pursuit of dao, participates and thus transforms the universe as well. For this reason, Confucius said: "It is man that can make the dao great, not the dao that can make man great".50 The concept of the "self searches in unity with dao" is beautifully explicated in Chung-yung (The Doctrine of the Mean):

"Only those who are absolutely sincere can fully develop their nature. If they can fully develop their nature, they can fully develop the nature of others. If they can then fully develop the nature of others, they can then fully develop the nature of things. If they can fully develop the nature of things, they can then assist in the transforming and nourishing process of Heaven and Earth. If they can assist in the transforming and nourishing process of Heaven and Earth, they can thus form a trinity with Heaven and Earth." ${ }^{51}$

\section{Conclusion}

While examining Confucius's conceptions of twodimensional personhood: the vertical dimension, the autonomous, self-cultivating one, and the horizontal dimension, the relational, altruistic one, the author has reflected on how doctors should approach their patients.

Persons in the Confucian sense comprise not merely the moral faculties of rationality and self consciousness that one is born with, but also moral accomplishment. This accomplishment arises in a cultural-historical tradition which stresses the individual's relationships with, and altruistic responsibility towards, others. When a person exercises autonomy, he is not choosing in a context-free, conceptual vacuum but considers himself a personin-relation, with many roles to play and responsibilities to take, in accordance with different relationships. A person cannot become fully human without fulfilling his role-specified relationoriented responsibilities; the Confucian personhood is to be realised through interpersonal transactions in human society.

Therefore when a doctor approaches his patient, he sees a person not only as a moral agent with autonomy and dignity to be respected, namely, the patient's concerns, preferences and choices to be respected and his rights protected. He also sees the patient as a relational being with certain family, community and social-historical contexts: a small self encompassed by one or many greater selves. In a Confucian context, the family, more than the individual, is often considered as one basic unit in the two aspects of doctor-patient relationships. Medical ethical decision making tends to respect the opinions and decisions made or agreed to by the family as a whole. Given the concept of relational personhood, the emphasis on family values, the large role and responsibility family usually take in caring for sick persons, and the interconnectedness and interdependence between family members, families must be taken seriously. After all, medical decisions taken by the patient often greatly influence family members (especially in a traditional Chinese family system), among whom the "morality of intimacy" cannot be replaced or overruled by the "ethics of impartiality, universality, and individualism of moral strangers". Moreover, when a doctor helps to maintain harmonious relationships among families and helps to bring agreement out of conflicts, he is in effect seeking to maximise the long term welfare of the patient.

Nevertheless, vices might be induced if one concentrates merely on the relational perspectives of persons. For example:

"emphasising filial piety (Shiaw), family values and the common good may cause the patient to reconcile their right of autonomous decision-making with the preferential choice of the families or social values, willy-nilly. Putting the public interest before self-interest and individual rights, in addition to highlighting the individual responsibility to the group, may lead to collectivism. A more 'paternalistic and patriarchal society' came from the historical tradition and social practice may naturally lead the doctor-patient-family relationship and medical decision-making to be inclined towards 'medical paternalism'. ${ }^{52}$

For these reasons, the autonomous perspective, the vertical dimension of persons is likely to be suppressed by the relational perspective, the horizontal dimension of persons, resulting in the sacrificing of a patient's rights and autonomy, and in the jeopardising of the cultivation of an autonomous person.

Hence, some may argue that there is no vertical dimension at all in the Confucian personhood. This is incorrect. The author has explained that the aim of Confucius's moral education is for the making of autonomous persons. To say that the vertical dimension and the horizontal dimension of Confucian personhood are incompatible with each other is also mistaken. They are two fundamentally coexisting, mutually supportive rather than exclusive, but sometimes competing, values in Confucius's ethics, which require constant balancing and reconciliation in practice. A (competent) patient's decision making concerning his personal moral 
values should unexceptionally be an autonomous choice of his own. On the other hand one should not forget the fact that, however such decisions are made, the patient, the agent, is always a person-inrelation. The tension might be difficult to resolve, but the traditional tendency of social orientation should surely be balanced by, and reconciled with, respecting the individual's rights and autonomy. In order to do this it is necessary to highlight the vertical dimension of a chun-tze, the values of being an autonomous, self-determined, self-reliant person and the respect due to that person, to the same level of importance as the horizontal dimension of a chun-tze, the realisation of self through altruism and incessantly participating in interpersonal interactions, which were emphasised so much in Confucian society.

Therefore, Chinese health care practitioners should be aware of how to protect their patients from being manipulated or coerced by the collectivist pressure (mostly from their families) and promote their autonomy without despising their traditional family values. For certain Western bioethicists, Confucian morality reminds them that the current ethos of individualism and regarding "respect for autonomy" as trump can never describe the whole picture of morality satisfactorily, nor can it give biomedical ethics a fundamental direction. To be a person is to be a part of a family and community where these are the locus for morality. The ultimate concern of this Confucian, two-dimensional person lies in fulfilling his duties in the various roles he plays, creating and maintaining the harmonious relationships with people and nature, contributing to the flourishing of human society, and at the end of the day being at one with "dao". The sense of human dignity and worth is not the natural criteria of rationality and self consciousness one is born with but a moral accomplishment for one to achieve.

\section{Acknowledgement}

The author would like to thank Professor John Harris and the colleagues participating in the Second Sino-German Symposium on Chinese Medical Ethics for their comments on the earlier drafts of this paper.

Daniel Fu-Chang Tsai MD, PhD (Health Care Ethics) is an Attending Physician at the Department of Family Medicine, National Taiwan University Hospital and a Lecturer at the College of Medicine, National Taiwan University, Taipei, Taiwan, Republic of China.

\section{References}

1 Szasz TS, Hollender MH. A contribution to the philosophy of medicine. Archives of Internal Medicine 1956;97:585-92.

2 Beauchamp TL, Childress JF. Principles of biomedical ethics [4th ed]. New York: Oxford University Press, 1994.

3 Downie RS, Calman KC. Healthy respect. Oxford: Oxford UniDownie RS, Calman
versity Press, 1994.

4 Engelhardt HT. The foundation of bioethics. New York: Oxford University Press, 1996.
5 Veatch R. Theories of bioethics. In: Global bioethics: the 4th World Congress of Bioethics program book. Proceedings of a conference presented by the International Association of Bioethics in conjunction with the Asian Bioethics Association, 4-7 Nov 1998, Tokyo, Japan

6 Macer DRJ. Bioethics is love of life: an alternative textbook. Christchurch, NZ: Eubios Ethics Institute, 1998.

7 Gillon R. Medical ethics: four principles plus attention to scope. British Medical fournal 1994;309:184-8.

$8 \mathrm{http}: / /$ www.counseling.org/resources/pracguide.htm

$9 \mathrm{http}: / /$ www.ada.org/prac/code/i-intro.html

$\begin{array}{rl}9 & \mathrm{http}: / / \text { www.ada.org/prac/code/1-intro.html } \\ 10 \mathrm{http} / / / \text { www.aafp.org/fpm/971000fm/ethics.html }\end{array}$

$10 \mathrm{http}: / /$ www.aafp.org/fpm/971000fm/ethics.htm

12 The Tri-Council Working Group was comprised of the Medical Research Council of Canada, the Natural Sciences and Engineering Research Council of Canada and the Social Sciences and Humanities Research Council of Canada, 1997.

13 Jaspers K. The great philosophers. London: Rupert Hart-Davis, 1962: 6

14 Wei JT. Hsien qin chi da zhe xue jia (The seven great philosophers before the Qin dynasty). Taipei: Buffalo Book Co, 1985:11.

15 Apart from Confucianism, Daoism and Buddhism are also very influential in Chinese culture. However, Confucianism has remained the position of cultural orthodoxy through the two millennia.

16 Tsai DFC. Ancient Chinese medical ethics and the four principles of biomedical ethics. Fournal of Medical Ethics 1999;25: 315-21.

17 Devine PE. The species principle and the potential principle. In: Brody B, Engelhardt HT, eds. Bioethics: readings and cases. New Jersey, Englewood Cliffs: Prentice-Hall Inc, 1987:136-41.

18 Engelhardt HT. The foundation of bioethics. New York: Oxford University Press, 1986:104.

19 Locke J. An essay concerning human understanding [book II]. London: Oxford University Press, 1964: ch 27.

20 Singer P. Practical ethics. Cambridge: Cambridge University Press, 1979:86. See also: Fletcher J. Indicators of humanhood: a tentative profile of man. The Hastings Center Report 1972;2:5. 21 Rudman S. Concepts of person and Christian ethics. Cambridge: Cambridge University Press, 1997:46-7.

22 Tooley $M$. The criterion of awareness of self as a continuing entity. See reference 17:146-52.

23 Harris J. The value of life. London: Routledge, 1985: 18.

24 See reference 4: 136-47.

25 Legge J, trans. The I Ching. New York: Dover Publications, 1963: 267

26 Chan WT. A source book in Chinese philosophy. New Jersey: Princeton University Press, 1969:29. Translation modified by the author.

27 Legge J, trans. The work of Mencius, the Chinese classics [vol II]. Taipei: SMC Publishing Inc, 1991: 294-5. Mencius is generally Taipei: SMC Publishing Inc, 1991: 294-5. Mencius is generally modified by the author.

28 Legge J, trans. Confucian analects, the Chinese classics [ $\mathrm{vol} \mathrm{I}]$. Taipei: SMC Publishing Inc, 1991: 300.

29 See reference $28: 287$

30 See reference $28: 288$

31 See reference 26: 72

32 See reference 28: 324

33 See reference $28: 324$. Translation modified by the author. 4 See reference 26: 20 .

S5 See refere $26: 41$.

36 Hsu FLK. Psychological homeostasis and jen: a conceptual tool for advancing psychological anthropology. American Anthrofor advancing psychological anthropol

37 Although Confucius never denied the creation of humankind by the transcendent heaven (tien), he did not refer to the moral personhood to be found in any particular act of the creation. On the other hand, communitarianism and feminist ethics also criticised liberalism for neglecting the communal and relational dimensions of persons.

38 Fingarette H. Confucius - the secular as sacred. New York/Hagerstown/San Francisco/London: Harper \& Row, 1972: 34.

39 Liang SM. Chung-kuo wen hua yao-i [The essential features of Chinese culture)] Hong Kong: Chi-cheng T'u-Shu Kung-Hsu, 1974. Cited in: Tao J. The moral foundation of welfare in Chinese society: between virtues and rights. In: Becker GK, ed. Ethics in business and society-Chinese and Western perspectives. Hong Kong: Springer, 1997:9-24.

40 Liang SM. Chung-kuo wen hua yao-i [The essential features of Chinese culture]. See reference 39: 94. Cited in: King AYC, Bond MH. The Confucian paradigm of man: a sociological view. In: Tseng WS, Wu DYH, eds. Chinese culture and mental health. Orlando: Academic Press Inc, 1985: 31. 
50 How should doctors approach patients? A Confucian reflection on personhood

41 Tu WM. Selfhood and otherness. Confucian thought: selfhood as creative transformation. New York: State University of New York Press, 1985: 113.

$42 \mathrm{Tu}$ WM. A Confucian perspective on learning to be human. See reference 41: 55

43 King AYC, Bond MH. The Confucian paradigm of man: sociological view. See reference 40: Tseng WS, Wu DYH: 31 .

44 Tao J. The moral foundation of welfare in Chinese society: between virtues and rights. See reference 39: 16.

45 See reference 20: 87

46 Lee KS. Some Confucianist reflections on the concept of the autonomous individual. fournal of Chinese Philosophy 1994;21:

autonom $49-59$.
47 Hansen C. Chinese philosophy and human rights: an application of comparative ethics. In: Becker GK, ed. Ethics in business and society-Chinese and Western perspectives. See reference 39: 108.

48 Elvin $M$. Between the earth and heaven: conception of the self in China. In Carrithers M, Colins S, Lukes S, eds. The category of the person. Cambridge: Cambridge University Press, 1987: 13-14.

49 See reference $42: 58$.

50 See reference 26: 44

51 See reference 26: 107-8.

52 See reference 16: 20-1. 